\title{
Investigate the anxiety between undergraduate and postgraduate nursing students and its relation to their socio-demographic characteristics
}

\author{
Paralikas Theodosios* ${ }^{* 1}$, Karaventza Vaia ${ }^{2}$, Kotrotsiou Evangelia ${ }^{1}$, Malliarou Maria ${ }^{1}$, Lahana Eleni ${ }^{1}$, Tsagalas Elias $^{3}$, \\ Kotrotsiou Styliani ${ }^{1}$ \\ ${ }^{1}$ University of Thessaly, Greece \\ ${ }^{2}$ School Nurse, Municipal Music School of Katerini, Pieria, Greece \\ ${ }^{3}$ University Hospital of Larisa, Greece
}

Received: November 20, 2019

Accepted: March 3, 2020

Online Published: March 18, 2020

DOI: $10.5430 /$ jnep.v10n6p73

URL: https://doi.org/10.5430/jnep.v10n6p73

\begin{abstract}
Objective: Anxiety is a warning sign for an upcoming risk and is a common reaction of most people reacting to stressful events. The purpose of this study was to investigate anxiety between undergraduate and postgraduate students in nursing and its relation to their socio-demographic characteristics.

Methods: This is a cross-sectional, quantitative study with a study sample of comprised of $\mathrm{n}=177$ nursing students, $\mathrm{n} 1=121$ undergraduate students and $\mathrm{n} 2=56$ postgraduate students. The collection of the empirical data was carried out using a fully structured and Self-reported questionnaire which recorded their individual characteristics and the State-Trait Anxiety Inventory (STAI). The statistical analysis was conducted using the software package SPSS.

Results: State anxiety was not found to differ significantly between undergraduate and postgraduate students. While Trait and Total Anxiety differed significantly, showing higher mean levels for undergraduate students. Moreover, the students of the last two years of study had a higher mean level of State Anxiety compared to the students of the first year of study.

Conclusions: The majority of undergraduate and postgraduate students showed relatively low levels of anxiety. Animportant factor to predict anxiety in undergraduate students was the year of study, while for the postgraduate students were age and marital status.
\end{abstract}

Key Words: Anxiety, Personality disorders, STAI, Adult students

\section{INTRODUCTION}

According to American Psychological Association (APA), anxiety is an emotion characterized by feelings of tension, worried thoughts and physical changes like increased blood pressure. ${ }^{[1]}$ The Anxiety and Depression Association of America (ADAA) adds that anxiety is a reaction to the stress. When stress lasts, becomes chronic and it can affect people's health by causing a number of symptoms such as headache, high blood pressure, chest pain, palpitations, skin rashes and sleep loss. ${ }^{[2]}$

Although the distinction between transient anxiety and anxiety as a personality trait began to emerge in the 1950s, Spielberger (1966) was the one who formed the theory of transient and permanentanxiety. ${ }^{[3]}$ According to Spielberger state anx-

*Correspondence: Paralikas Theodosios; Email: paralikas@teilar.gr; Address: University of Thessaly, Greece. 
iety refers to an existing or immediate emotional state characterized by anxiety and tension. Trait anxiety refers to the predisposition to perceive specific situations as threatening and to react to them with varying levels of transient anxiety. State anxiety is characterized by subjective, perceived feelings of anxiety and tension, accompanied or associated with the activation or stimulation of the autonomic nervous system. Trait anxiety is an acquired behavioral predisposition that makes the individual perceive a set of objectively non-threatening situations as threatening and reactive to them with anxiety disproportionate in intensity relative to the size of the objective risk. Individuals with high trait anxiety perceive more situations as threatening and respond to threatened situations with higher levels of state anxiety status or both.

The beginning of student life is an important period of transition from adolescence to young adulthood. It is a period with various lifestyle changes that start with moving away from home and independence from the family. ${ }^{[4]}$ This situation marks a change in the way of living, with the management of everyday economic problems, new social surroundings, academic requirements as well as physical and emotional problems. ${ }^{[5]}$

Several times, anxiety leads to the adoption of harmful health methods such as smoking, alcohol, substance abuse, lack of sleep, and limited physical activity. ${ }^{[6]}$ Thus, the mental health of students is affected by stressful stimuli throughout the academic years. Of courseeach student faces anxiety in a different way. It depends on his personality, character, and elements such as self-awareness and self-confidence that limit the chances of anxiety attacks. ${ }^{[7]}$

The purpose of this study was to investigate anxiety levels between undergraduate and postgraduate nursing students and their relationship to their socio-demographic characteristics.

\section{Background}

Academic stress is the most common emotional and mental state experienced by students during their student years. Stress is the result of a wide range of issues. It involves a challenging path with a different education system, high social expectations, given the later competition in the labor market, emotional and mental burden including test examinations. ${ }^{[8]}$

Anxiety among undergraduate and postgraduate students is a multi-faceted situation, arising both from academic and nonacademic factors, including socio-cultural, environmental and psychological characteristics.Stress levels can be staggered in significant proportions by a multitude of students and show signs of anxiety. ${ }^{[9]}$ In some students, anxiety can cause negative emotions, both academic and personal, discomfort and affect their career. However, a proportion of students may be positively motivated to be associated with the anxiety. ${ }^{[10]}$

In a survey conducted to investigate quality of life in postgraduate students, it was found that they are experiencing more stress during their training. They are emotionally vulnerable especially during the first year of studies and face adaptation problems. Additionally, students belonging to this category are among the high-risk groups for the development of emotional disorders during their postgraduate studies. ${ }^{[11]}$

During the examination period, student anxiety is increasing. It is a period where the individual is experiencing an evaluation process with possible failure or success result. Irrespective of age, gender, economic and social status anxiety can occur with a continuous increase in the youth population, mainly in the student, which stems from the requirements of the academic career. The most common forms of anxiety are transient or instantaneous (state anxiety) and generalized anxiety associated with the overall academic performance of students. ${ }^{[12,13]}$

In particular, several surveys for students, mostly early years of studies, have shown that anxiety during this period is due to poor organization and poor preparation to participate in the examination process. Furthermore, the transitional situation, from secondary education to university, has a major role in adaption difficulties to new requirements. It has been found that state anxiety, which occupies the students, increases more at the time of the examination whether it is oral or written in relation to the generalized anxiety prevailing throughout the examination period. In addition, state anxiety before the start of the examination period is associated with nervousness and anxiety reactions and is significantly reduced at the end of the exam or/and the positive performance of the students in the course. However, even after the exam, anxiety is an important risk factor for physical and emotional exhaustion of students. ${ }^{[14,15]}$

Students appear to have consistently high levels of anxiety and depression in relation to the general population throughout their studies as they are burdened by stressors factors that affect physical and mental health. ${ }^{[16]}$ High levels of anxiety are often associated with low self-esteem, economic problems, oppression from the family environment, and exhaustion during the exam, and lack of time. Consequences of the accumulated stress of the students are physical and mental exhaustion, anxiety that is often unmanageable, depression, increased alcohol and nicotine use. ${ }^{[17]}$ Consequently, students may develop dysfunctional management modes and solving the aforementioned problems with an impact on both 
interpersonal relationships and on health and academic obligations. If there is no timely treatment, there may be a risk of interruption of studies. ${ }^{[13]}$ Healthcare specialists and healthcare students, have higher levels of anxiety compared to other occupations because of their high job demands and responsibilities. Higher levels of anxiety are noted in clinical training with increased blood pressure and heart rate. ${ }^{[18]}$

\section{MethodS}

\subsection{Study design and sample}

This is a Descriptive correlational Cross-Sectional Study.The study sample was comprised of Undergraduate and Postgraduate Nursing Students. Most specifically a total of 177 nursing students, took part in the study. They are undergraduate students from the Nursing Department of the Technological Educational Institute (TEI) of Thessaly (n:121) and Postgraduate students from the Postgraduate Program in Mental Health/Nursing Department/TEI of Thessaly and the Postgraduate Program in Primary Health Care/Medicine Department of Medicine/University of Thessaly and Nursing Department/TEI of Thessaly (n:56). The sampling method applied was that of the Non-Probability Sampling, and in particular the Convenience Sampling technique.

\subsection{Instrument}

The collection of the empirical data of the research was carried out using a fully structured and self-completed questionnaire. In particular, the questionnaire consisted of two parts: (A) Form of recording theirof individual characteristics. This part included questions about the socio-demographic characteristics (gender, age, marital status, year of study, place of permanent residence and working status) of undergraduate and postgraduate nursing students. (B).

The State-Trait Anxiety Inventory (STAI) of Spielberger et al., (1970) was used as a measure of Anxiety. Spielberger's STAI Scale is a self-report questionnaire that has been used in numerous surveys around the world as a tool for measuring anxiety. The State-Trait Anxiety Inventory (STAI) is a psychological inventory based on a 4-point Likert scale and consists of 40 questions on a self-report basis. The STAI measures two types of anxiety - state anxiety, or anxiety about an event, and trait anxiety, or anxiety level as a personal characteristic. Direct expressions state negative feelings while reverse expressions state positive feelings. There are ten reverse expressions in the state anxiety sub-scale, items no. $1,2,5,8,10,11,15,16,19$ and 20 . There are seven reverse expressions in the trait anxiety sub-scale, items no. 21, 26, $27,30,33,36$ and 39 . The scores obtained from both scales can theoretically vary between 20 and 80 . Higher scores are positively correlated with higher levels of anxiety. The minimum score of each Subscale is 20 and the maximum is Published by Sciedu Press
80, while the score for the sum scale ranges from 40 to 160. Higher scores indicate higher levels of Anxiety. ${ }^{[19]}$

The Greece-adapted version of the STAI Scale used in this research work was done by Liakos and Giannitsi (1984). ${ }^{[20]}$

\subsection{Procedure}

The survey data collection took place between November and December 2017. The questionnaire was provided to the students and the appropriate instructions for completing it were given at the university facilities. Purposive sampling procedure was applied and 177 students comprised the study sample. The participation of the students was voluntary, anonymous and all ethical rules of research were ensured. This paper was approved by the human subjectsethics board of the Committee of Education and Research of TEI of Thessaly and was conducted in accordance with the Helsinki Declaration of 1975, as revised in 2013.

\subsection{Data analysis}

The empirical research material was processed and statistically analyzed with the "SPSS (Statistical Package for the Social Science) 19.0 for Windows" software package, using methods of Descriptive and Inferential Statistics.

In particular, descriptive analysis included the frequency distribution for the qualitative variables (absolute and relative\% frequency) as well as estimations of the position and variance parameters for the quantitative variables (mean, standard deviation, median, minimum and maximum). Induction analysis applied in order to investigate possible correlations. Reliability of STAI Anxiety Scale was tested using Cronbach alfa (see Table 1) .More in detail, the Pearson Correlation Coefficient ( $\mathrm{r}$ ), $t$-test for independent samples, one-way analysis of variance (ANOVA), chi-square test for independency and multiple linear regression were used. The levels of significance ( $p$ value) were twofold and the level of acceptable statistical significance was set to $p<.05$. Normality was tested using Kolmogorov-Smirnov and Shapiro-Wilk (see Table 2).

Table 1. Reliability test for STAI Anxiety Scale of Undergraduate and Postgraduate Nursing Students $(n=177)$

\begin{tabular}{lllll}
\hline STAI Scale & $\begin{array}{l}\text { Cronbach's } \\
\text { alpha }\end{array}$ & Mean \pm SD & Median & Min-Max \\
\hline State anxiety & 0.88 & $41.64 \pm 9.49$ & 41.00 & $20-70$ \\
Trait anxiety & 0.86 & $42.82 \pm 8.89$ & 43.00 & $21-67$ \\
Total anxiety & 0.92 & $84.46 \pm 16.86$ & 83.00 & $41-137$ \\
\hline
\end{tabular}

\section{Results}

\subsection{Sample}

The socio-demographic characteristics of undergraduate and postgraduate nursing students are given in Table 3 . 
Table 2. Tests of Normality

\begin{tabular}{|c|c|c|c|c|c|c|}
\hline \multirow{2}{*}{ STAI Scale and Subscales } & \multicolumn{3}{|c|}{ Kolmogorov-Smirnov } & \multicolumn{3}{|c|}{ Shapiro-Wilk } \\
\hline & Statistic & df & Sig. & Statistic & df & Sig. \\
\hline STAI (Stateanxiety) & .065 & 177 & .068 & .989 & 177 & .174 \\
\hline STAI (Traitanxiety) & .062 & 177 & .092 & .990 & 177 & .277 \\
\hline STAI (Totalanxiety) & .053 & 177 & .200 & .991 & 177 & .364 \\
\hline
\end{tabular}

Table 3. Socio-demographic characteristics of undergraduate and postgraduate nursing students $(n=177)$

\begin{tabular}{|c|c|c|c|c|}
\hline Characteristics & $\begin{array}{l}\text { Undergraduate students } \\
(\mathrm{n}=121)\end{array}$ & $\begin{array}{l}\text { Postgraduate students } \\
(\mathrm{n}=56)\end{array}$ & Statistical test & $p$ value \\
\hline \multicolumn{5}{|l|}{ Gender } \\
\hline Male & $27(22.3 \%)$ & $13(23.2 \%)$ & \multirow[t]{2}{*}{$\chi^{2}=0.018$} & \multirow[t]{2}{*}{.894} \\
\hline Female & $94(77.7 \%)$ & $43(76.8 \%)$ & & \\
\hline Age (years) & $20.37 \pm 3.66$ & $35.23 \pm 8.82$ & $t=12.135$ & $<.001$ \\
\hline \multicolumn{5}{|l|}{ Marital status } \\
\hline Single & $119(98.3 \%)$ & $27(48.2 \%)$ & \multirow{3}{*}{$\chi^{2}=66.689$} & \multirow{3}{*}{$<.001$} \\
\hline Married & $2(1.7 \%)$ & $25(44.6 \%)$ & & \\
\hline Divorced or Widowed & $0(0.0 \%)$ & $4(7.1 \%)$ & & \\
\hline \multicolumn{5}{|l|}{ Year of studies } \\
\hline 1 st half of study & $67(55.4 \%)$ & $0(0.0 \%)$ & \multirow{6}{*}{$\chi^{2}=49.895$} & \multirow{6}{*}{$<.001$} \\
\hline 2nd half of study & $54(44.6 \%)$ & $56(100 \%)$ & & \\
\hline $1^{\circ}$ year & 67 & 0 & & \\
\hline $2^{\circ}$ year & 0 & 56 & & \\
\hline $3^{\circ}$ year & 27 & - & & \\
\hline $4^{\circ}$ year & 27 & - & & \\
\hline \multicolumn{5}{|c|}{ Place of permanent residence } \\
\hline City & $78(64.5 \%)$ & $47(83.9 \%)$ & \multirow{3}{*}{$\chi^{2}=8.461$} & \multirow{3}{*}{.015} \\
\hline Small town & $17(14.0 \%)$ & $6(10.7 \%)$ & & \\
\hline Village & $26(21.5 \%)$ & $3(5.4 \%)$ & & \\
\hline \multicolumn{5}{|l|}{ Work situation } \\
\hline Full-time employee & $2(1.7 \%)$ & $41(73.2 \%)$ & \multirow{3}{*}{$\chi^{2}=109.581$} & \multirow{3}{*}{$<.001$} \\
\hline Part-time employee & $12(9.9 \%)$ & $5(8.9 \%)$ & & \\
\hline Unemployed & $107(88.4 \%)$ & $10(17.9 \%)$ & & \\
\hline
\end{tabular}

Note. The data is given as $\mathrm{n}(\%)$ for the qualitative variables and mean \pm sd for the quantitative variables.

\subsection{Levels of anxiety}

Descriptive analyses for the STAI are reported in Table 1. Both Undergraduate and Postgraduate Nursing students report relatively low levels of overall as well as state- and trait-anxiety.

\subsection{Anxiety difference of undergraduate and postgradu- ate nursing students}

Table 4 shows bivariate analysis using t-test. Undergraduate students show higher level of both trait- and total anxiety than Postgraduate students ( $p<.01$ and $p<.05$, respectively). No significant differences were found in state-anxiety levels between the two groups.
Table 4. Comparisons of Anxiety levels between

undergraduate and postgraduate nursing students $(\mathrm{n}=177)$

\begin{tabular}{llll}
\hline Level of education & STAI & & \\
\cline { 2 - 4 } Nursing Students & State anxiety & Trait anxiety & Total anxiety \\
\hline Undergraduate $(\mathrm{n}=121)$ & $42.30 \pm 8.85$ & $44.08 \pm 8.61$ & $86.38 \pm 15.86$ \\
Postgraduate $(\mathrm{n}=56)$ & $40.23 \pm 10.69$ & $40.09 \pm 8.94$ & $80.32 \pm 18.32$ \\
$t$ & 1.350 & 2.835 & 2.249 \\
$p$ value & .179 & .005 & .026 \\
\hline Note. The data is given as mean $\pm \mathrm{sd}$. & &
\end{tabular}

Note. The data is given as mean $\pm \mathrm{sd}$.

3.4 Anxiety and socio-demographic characteristics of undergraduate nursing students

From the investigation of the relation between the sociodemographic of the undergraduate students of Nursing and 
Anxiety emerged that the only significant factor for state anxiety is the year of study, $(t$ test $=2.052, \mathrm{df}=119 ; p=$ .042) (see Table 5). More in detail, the students of the last two years had a higher mean level of state anxiety versus the first-year students $(44.11 \pm 9.59$ vs. $40.84 \pm 7.98)$. Also, analysis shows that there are no significant factors for trait and total anxiety for undergraduate nursing students.

Table 5. Anxiety and socio-demographic characteristics of Undergraduate Nursing Students $(\mathrm{n}=121)$

\begin{tabular}{|c|c|c|c|}
\hline \multirow{2}{*}{ Characteristics } & \multicolumn{3}{|l|}{ STAI } \\
\hline & State anxiety & Trait anxiety & Total anxiety \\
\hline \multicolumn{4}{|l|}{ Gender } \\
\hline Male & $41.85 \pm 10.46$ & $42.70 \pm 10.68$ & $84.56 \pm 20.28$ \\
\hline Female & $42.43 \pm 8.39$ & $44.48 \pm 7.94$ & $86.90 \pm 14.43$ \\
\hline$T$ & 0.296 & 0.944 & 0.677 \\
\hline$p$ value & .768 & .347 & .500 \\
\hline \multicolumn{4}{|l|}{ Age (years) } \\
\hline$R$ & -0.038 & -0.074 & -0.062 \\
\hline$p$ value & .675 & .420 & .502 \\
\hline \multicolumn{4}{|l|}{ Year of studies } \\
\hline 1st half of study & $40.84 \pm 7.98$ & $43.54 \pm 8.40$ & $84.37 \pm 14.66$ \\
\hline 2nd half of study & $44.11 \pm 9.59$ & $44.76 \pm 8.90$ & $88.87 \pm 17.05$ \\
\hline$T$ & 2.052 & 0.775 & 1.560 \\
\hline$p$ value & .042 & .440 & .121 \\
\hline \multicolumn{4}{|c|}{ Place of permanent residence } \\
\hline City & $41.92 \pm 8.48$ & $43.64 \pm 8.30$ & $85.56 \pm 15.09$ \\
\hline Small city/Village & $42.98 \pm 9.55$ & $44.88 \pm 9.20$ & $87.86 \pm 17.25$ \\
\hline$T$ & 0.626 & 0.758 & 0.761 \\
\hline$p$ value & .533 & .450 & .448 \\
\hline \multicolumn{4}{|l|}{ Work situation } \\
\hline Employee & $44.57 \pm 8.36$ & $47.21 \pm 8.43$ & $91.79 \pm 15.86$ \\
\hline Unemployed & $42.00 \pm 8.90$ & $43.67 \pm 8.60$ & $85.67 \pm 15.80$ \\
\hline$T$ & 1.023 & 1.454 & 1.361 \\
\hline$p$ value & .308 & .149 & .176 \\
\hline
\end{tabular}

Note. The data is given as mean $\pm \mathrm{sd}$.

3.5 Anxiety and socio-demographic characteristics of Postgraduate Nursing Students

Using the multivariate analysis for the investigation of the relationship between the socio-demographic characteristics of the undergraduate students of Nursing and State Anxiety, revealed that the year of study is a significant predictor of state anxiety. In particular, the mean state anxiety for undergraduate nursing students in the last two years was 3.27 higher than in the first year of study (adjusted $\mathrm{b}=3.275$; $p=$ .042) (see Table 6).

Table 6. Multiple linear regression (stepwise method) with dependent variables the State Anxiety of the STAI Scale and independent variable characteristics of undergraduate nursing students $(n=121)$

\begin{tabular}{|c|c|c|c|c|}
\hline \multirow{2}{*}{ Independent variables } & \multicolumn{4}{|c|}{ State anxiety } \\
\hline & Adjusted b & SE & $95 \%$ CI & $p$ value \\
\hline Constant ( $\alpha)$ & 37.561 & 2.441 & 32.726 up to 42.395 & $<.001$ \\
\hline \multicolumn{5}{|l|}{ Year of study } \\
\hline 1st half of study & 0 & & & .042 \\
\hline 2nd half of study & 3.275 & 1.596 & 0.114 up to 6.436 & \\
\hline
\end{tabular}

\subsection{Anxiety and socio-demographic characteristics of Postgraduate Nursing Students}

From the investigation of the relationship between the sociodemographic of postgraduate nursing and Anxiety Students,

Published by Sciedu Press revealed that there are two significant factors for state anxiety, age $(\mathrm{r}=-0.303, \mathrm{df}=54 ; p=0.023)$ and marital status $(\mathrm{F}=4.571$, df $1=2 ; \mathrm{df} 2=53 ; p=.023)$ (see Table 7). More in detail, the results showed that as the age of the students 
increased, the levels of state anxiety reduced. Moreover, Nursing and state anxiety, revealed that the marital status is a married students showed a lower mean level of stateanxiety compare tosingle students $(36.64 \pm 10.68$ versus 44.41 \pm 9.12 ). Also, divorced/widowed students showed a lower mean level of state anxiety compare to single students $(34.50$ \pm 12.40 versus $44.41 \pm 9.12$ ). Using the multivariate analysis for the investigation of the relationship between the sociodemographic characteristics of the postgraduate students of significant predictor of state anxiety. In particular, the mean value of the state anxiety of married and divorced/widowed postgraduate nursing students was 7,767 units and 9,907 units, respectively, smaller than single students (adjusted $\beta=-7.767 ; p=.007$ and adjusted $\beta=-9.907 ; p=.070$, respectively) (see vTable 8 ).

Table 7. Anxiety and socio-demographic characteristics of Postgraduate Nursing Students $(\mathrm{n}=56)$

\begin{tabular}{|c|c|c|c|}
\hline \multirow{2}{*}{ Characteristics } & \multicolumn{3}{|l|}{ STAI } \\
\hline & State anxiety & Trait anxiety & Total anxiety \\
\hline \multicolumn{4}{|l|}{ Gender } \\
\hline Male & $41.31 \pm 11.24$ & $40.46 \pm 10.51$ & $81.77 \pm 20.07$ \\
\hline Female & $39.91 \pm 10.63$ & $39.98 \pm 8.55$ & $79.88 \pm 17.99$ \\
\hline$T$ & 0.411 & 0.170 & 0.323 \\
\hline$p$ value & .683 & .866 & .748 \\
\hline \multicolumn{4}{|l|}{ Age (years) } \\
\hline$R$ & -0.303 & -0.277 & -0.312 \\
\hline$p$ value & .023 & .039 & .019 \\
\hline \multicolumn{4}{|l|}{ Marital status } \\
\hline Single (1) & $44.41 \pm 9.12$ & $42.96 \pm 9.18$ & $87.37 \pm 16.81$ \\
\hline Married (2) & $36.64 \pm 10.68$ & $38.32 \pm 7.67$ & $74.96 \pm 17.09$ \\
\hline Divorced or Widowed (3) & $34.50 \pm 12.40$ & $31.75 \pm 8.50$ & $66.25 \pm 20.32$ \\
\hline $\mathrm{F}$ & 4.571 & 4.022 & 4.844 \\
\hline$p$ value & .015 & .024 & .012 \\
\hline \multirow[t]{2}{*}{ Post Hoc Test (LSD) } & $(1)>(2) p=.007$ & $(1)>(2) p=.050$ & $(1)>(2) p=.012$ \\
\hline & $(1)>(3) p=.070$ & $(1)>(3) p=.017$ & $(1)>(3) p=.026$ \\
\hline \multicolumn{4}{|c|}{ Place of permanent residence } \\
\hline City & $40.83 \pm 10.74$ & $40.45 \pm 8.72$ & $81.28 \pm 18.02$ \\
\hline Small city/Village & $37.11 \pm 10.45$ & $38.22 \pm 10.40$ & $75.33 \pm 20.17$ \\
\hline$T$ & 0.955 & 0.680 & 0.890 \\
\hline$p$ value & .344 & .499 & .377 \\
\hline \multicolumn{4}{|l|}{ Work situation } \\
\hline Full-time employee & $39.24 \pm 10.44$ & $39.54 \pm 8.37$ & $78.78 \pm 17.43$ \\
\hline Part-time employee & $41.60 \pm 9.13$ & $43.40 \pm 5.60$ & $85.00 \pm 12.27$ \\
\hline Unemployed & $43.60 \pm 12.61$ & $40.70 \pm 12.46$ & $84.30 \pm 24.34$ \\
\hline $\mathrm{F}$ & 0.705 & 0.435 & 0.535 \\
\hline$p$ value & .499 & .649 & .589 \\
\hline
\end{tabular}

Note. The data is given as mean \pm sd.

Table 8. Multiple linear regression (stepwise method) with dependent variables the State Anxiety of the STAI Scale and independent variables the characteristics of Postgraduate Nursing Students $(n=56)$

\begin{tabular}{|c|c|c|c|c|}
\hline \multirow{2}{*}{ Independent variables } & \multicolumn{4}{|c|}{ State anxiety } \\
\hline & Adjusted b & SE & $95 \% \mathrm{CI}$ & $p$ value \\
\hline Constant (a) & 44.407 & 1.936 & $40.525-48.290$ & $<.001$ \\
\hline \multicolumn{5}{|l|}{ Marital status } \\
\hline Single (1) & 0 & & & \\
\hline Married (2) & -7.767 & 2.792 & $-13.367--2.168$ & .007 \\
\hline Divorced or Widowed (3) & -9.907 & 5.388 & $-20.715-0.900$ & .070 \\
\hline
\end{tabular}

Note. Adjusted $R^{2}=11.5 \% ; \mathrm{F}=4.571 ; p=.015$ 
The results regarding trait anxiety revealed as significant factors age $(\mathrm{r}=-0.277, \mathrm{df}=54 ; p=.039)$ and marital status $(\mathrm{F}=4.022$, df $1=2$; df $2=53 ; p=.024)$ of students (see Table 7). More in detail, the results showed that as the age of the students increased, the levels of trait anxiety reduced. Furthermore, married students showed a lower mean level of trait anxiety compare to single students (38.32 \pm 7.67 vs. $42.96 \pm 9.18$ ). Also, divorced/widowed students showed a lower mean level of state anxiety compare to single students $(31.75 \pm 8,50$ versus $42.96 \pm 9.18)$. Using the multivariate analysis for the investigation of the relationship between the socio-demographic characteristics of the postgraduate students of Nursing and trait anxiety revealed that the marital status is a significant predictor of trait anxiety. In particular, the mean value of the trait anxiety of married and divorced/widowed postgraduate nursing students was 4.64and 11.21, respectively, smaller than single students (adjusted $\beta=-4.643 ; p=.050$ and adjusted $\beta=-11.213 ; p=$ .017 , respectively) (see Table 9).

Table 9. Multiple linear regression (stepwise method) with dependent variables the Trait Anxiety of the STAI Scale and independent variables the characteristics of Postgraduate Nursing Students $(\mathrm{n}=56)$

\begin{tabular}{lllll}
\hline \multirow{2}{*}{ Independent variables } & \multicolumn{2}{l}{ Trait anxiety } & & $\boldsymbol{p}$ value \\
\cline { 2 - 5 } & Adjusted b & SE & 95\% CI & $<.001$ \\
\hline Constant ( $\alpha)$ & 42.963 & 1.633 & 39.687 up to 46.239 & \\
Marital status & & & & .050 \\
Single (1) & 0 & & -9.367 up to 0.080 & .017 \\
Married (2) & -4.643 & 2.355 & -20.333 up to -2.093 & \\
Divorced or Widowed (3) & -11.213 & 4.547 & & \\
\hline
\end{tabular}

Note. Adjusted $R^{2}=9.9 \% ; \mathrm{F}=4.022 ; p=.024$

Finally, results regarding total anxiety revealed as significant factors age $(\mathrm{r}=-0.312, \mathrm{df}=54 ; p=.019)$ and marital status $(\mathrm{F}=4.844$, df $1=2 ;$ df $2=53 ; p=.012)$ of students (see Table 7). More in detail, the results showed that as the age of the students increased, the levels of total anxiety reduced. Furthermore, married students $(74.96 \pm 17.09$ vs. $87.37 \pm$ $16.81)$ and divorced/widowed students (66.25 \pm 20.32 vs. $87.37 \pm 16.81$ ) showed a lower mean level of total anxiety compare to single students. Using the multivariate analysis for the investigation of the relationship between the sociodemographic characteristics of the postgraduate students of Nursing and total anxiety, revealed that the marital status is a significant predictor of total anxiety. In particular, the mean value of the total anxiety of married and divorced/widowed postgraduate nursing students was 12.41 and 21.12 , respectively, smaller than single students (adjusted $\beta=-12.410 ; p$ $=.012$ and adjusted $\beta=-21.120 ; p=.026$, respectively) (see Table 10).

Table 10. Multiple linear regression (stepwise method) with dependent variables the Total Anxiety and independent variables the characteristics of Postgraduate Nursing Students $(n=56)$

\begin{tabular}{lllll}
\hline \multirow{2}{*}{ Independent variables } & \multicolumn{2}{l}{ Total anxiety } & & \\
\cline { 2 - 5 } & Adjusted b & SE & 95\% CI & p value \\
\hline Constant ( $\alpha)$ & 87.370 & 3.302 & 80.747 up to 93.993 \\
Marital status & & & & \\
Single (1) & 0 & & & \\
Married (2) & -12.410 & 4.762 & -21.962 up to -2.859 & .012 \\
Divorced or Widowed (3) & -21.120 & 9.192 & -39.558 up to -2.683 & .026 \\
\hline Note. Adjusted $R^{2}=12.3 \% ; \mathrm{F}=4.844 ; p=.012$ & & &
\end{tabular}

\section{Discussion}

Anxiety is an integral part of human life. It is a phenomenon that affects people regardless of age, gender and socioeconomic background and has a negative impact both at the mental, social and physical level.

Literature reveals that anxiety has a huge impact on learning. Verifying anxiety level in nursing students is highly

Published by Sciedu Press important for the nurse educational process, because the first contact with the hospital setting itself can bring fear and impotence. The negative impact of anxiety may be reduced when faculty acknowledges anxiety and provide a supportive learning environment for nursing students where mistakes are accepted as a part of the learning process.

In our studyas far as the socio - demographic characteris- 
tics of undergraduate and postgraduate nursing students are concerned, there were no gender differences in the survey, while there were differences in the year of study, place of residence, age, work and family situation. Similarly, in a survey conducted in Bosnia and Herzegovina among undergraduate nursing students, there were no gender differences in the onset of anxiety. ${ }^{[5]}$

The mean state anxiety scores of both undergraduate and postgraduate nursing studentswas low. Although the number of students who presented low anxiety level is small the need of support to these students is essential and can be decisive when it is realized that the anxiety is severe enough to damage their learning or their clinical training.Traitanxiety and total anxiety score of undergraduate nursing students was found to be higher than that of postgraduate nursing students. A previous study conducted in 2009 amongst undergraduate students in Spain also showed higher rates of anxiety. ${ }^{[21]}$ An important factor for high anxiety rates of undergraduate nursing students is the clinical part of their studies as they come into contact with the human body for the first time, they feel a lot of insecurity as they are not prepared for challenging situations as nursing programs are intense, complex, and require long hours in the clinical setting. ${ }^{[22]}$

\section{REFERENCES}

[1] American Psychological Association (APA). Anxiety. [Internet]. 2020[cited 2020 March7]. Available from: https://www . apa.or g/topics/anxiety

[2] Anxiety and Depression Association of America (ADAA). Stress. [Internet]. [cited 2020 March9]. Available from: https://adaa.o rg/understanding-anxiety/related-illnesses/stress

[3] Spielberger CD. Theory and research on anxiety. In CD Spielberger, Anxiety and behavior. New York: Academic Press; 1966; 3-20p. https://doi .org/10.1016/B978-1-4832-3131-0.50006-8

[4] Racic M, Todorovic R, Ivkovic N, et al. Self-Perceived Stress in Relation to Anxiety, Depression and Health-related Quality of Life among Health Professions Students: A Cross-sectional Study from Bosnia and Herzegovina. Zdr Varst. 2017 Oct 9; 56(4): 251-259. PMid:29062400 https://doi.org/10.1515/sjph-2017-0034

[5] Murphy L, DenisR, Ward CP, et al. Tartar. Academic stress differentially influences perceived stress, salivary cortisol, and Immunoglobulin-Ain undergraduate students. Stress. $2010 \mathrm{Jul}$; 13(4): 365-70. PMid:20536338 https://doi.org/10.3109/10253891 003615473

[6] Stults-Kolehmainen MA, Sinha R. The effects of stress on physical activity and exercise.Sports Med. 2014 Jan; 44(1): 81-121. PMid:24030837 https://doi.org/10.1007/s40279-013-009 $0-5$

[7] Patitsa C, Chaniotis D, Chaniotis F, et al. The relationship of selfesteem, body mass index, state anxiety and physical activity at college
This study found that the year of study is a significant predictor of state anxiety. This finding can be explained by the fact that the experience of taking care of the sick, interacting with patients, and dealing with death during clinical placement may have caused psychological problems for our undergraduate nursing students as it was similarly shown in a study conducted by Chen et al. (2015). ${ }^{[23]}$

\section{Limitations}

A significant limitation of the present study was the small sample size and sample selection from a particular geographical area of Greece. For this purpose, you will consider future research into a larger sample size by recording more social-demographic characteristics of the students.

\section{Concussion}

In conclusion, there have not been many researches involving nursing students. For this research, the majority of undergraduate and postgraduate students showed relatively low levels of anxiety. An important factor for undergraduate students was the year of study; while for the postgraduate students were marital status and age.

\section{CONFLiCTS OF INTEREST Disclosure}

The authors declare that there is no conflict of interest. students. e-Journal of Science \& Technology. 2011; 6(3): 103-117 (in Greek).

[8] Ramli NH, Alavi M, MehrinezhadSA, et al. Academic Stress and SelfRegulation among University Students in Malaysia: Mediator Role of Mindfulness.Behavioral Sciences. 2018; 8(1): 12. PMid:29342910 https://doi.org/10.3390/bs8010012

[9] Bedewy D, Gabriel A. Examining perceptions of academic stress and its sources among university students: The Perception of Academic Stress Scale. Health Psychol Open. 2015 Jul 30; 2(2): 1-9. PMid:28070363 https://doi.org/10.1177/20551029155967 14

[10] Mark G, Smith AP. Occupational stress, job characteristics, coping, and the mental health of nurses. BrJ Health Psychol. 2012; 17(3): 505521. PMid:22107162 https://doi .org/10.1111/j . 2044-828 7.2011.02051.x

[11] Velana M, Barbouni A, Merakou K, et al. Research of quality of life in students of programmes of postgraduate studies in Public Health. Archives of Hellenic Medicine/ArheiaEllenikesIatrikes. 2012 Mar/Apr; 29(2): 195-201 (in Greek).

[12] Mellanby J, ZimdarsA. Trait anxiety and final degree performance at the University of Oxford. Higher Education. 2010; 61: 357-370. https://doi.org/10.1007/s10734-010-9335-5

[13] Kadapatti MG, Vijayalaxmi AH. Stressors of academic stress-a study on pre-university students. Indian Journal of Scientific Research. 2012; 3(1): 171-175.

[14] Kulsoom B, Afsar NA. Stress, anxiety, and depression among medical students in a multiethnic setting. Neuropsychiatric Dis- 
ease and Treatment. 2015; 11: 1713-1722. PMid:26213470 https : //doi.org/10.2147/NDT.S83577

[15] Rizvi H, Awaiz M, Ghanghro Z, et al. Pre-examination stress in second year medical students in a government college. J Ayub Med Coll Abbottabad. 2010; 22(2): 152-155.

[16] Andrews B, Wilding JM. The relation of depression and anxiety to life-stress and achievement in students. British Journal of Psychology. 2004; 95(4): 509-521. PMid:15527535 https://doi.org/10.1 $348 / 0007126042369802$

[17] Schmidt L, Sieverding M, ScheiterF, et al. Predicting and explaining students' stress with the Deman-Control Model: Does neuroticism also matter? Education Psychology. 2015; 35(4): 449-465. https://doi.org/10.1080/01443410.2013.857010

[18] Sharma B, Wavare R. Academic stress duo to depression among medical and para-medical students in an Indian medical college: Health initiatives cross sectional study. Journal of Health Sciences. 2013; 3(5): 29-38.
[19] Spielberger CD, Gorsuch RL, Lushene RE. STAI Manual for the State-Trait Anxiety Inventory. Palo Alto, CA: Consulting Psychologists Press; 1970-Inc.

[20] Liakos A, Gianitsi S. The validity and reliability of the revised Greek anxiety scale by Spielberger. Engefalos. 1984; 21: 71-76.

[21] Jimenez C, Navia-Osorio PM, Diaz CV. Stress and health in novice and experienced nursing students. Journal of Advanced Nursing. 2010; 66(2): 442-455. PMid:20423427 https://doi.org/10.1 $111 / j .1365-2648.2009 .05183 . x$

[22] Chernomas WM, Shapiro C. Stress, depression, and anxiety among undergraduate nursing students. International Journal of Nursing Education Scholarship. 2013; 10(1): 255-266. https ://doi .org/10 .1515/ijnes-2012-0032

[23] Chen CJ, ChenYC, Sung HC, et al. The prevalence and related factors of depressive symptoms among junior college nursing students: a cross-sectional study. Journal of Psychiatric and Mental Health Nursing. 2015; 22: 590-598. PMid:26149070 https: //doi.org/10.1111/jpm.12252 